\title{
Risk factors associated with occurrence of COVID-19 among household persons exposed to patients with confirmed COVID-19 in Qingdao Municipal, China
}

\author{
Hualei Xin ${ }^{1}$, Fachun Jiang ${ }^{1}$, Aili Xue ${ }^{2}$, Jiwei Liang ${ }^{1}$, Jingfei Zhang ${ }^{1}$, Feng Yang ${ }^{1}$, and Yalin \\ $\operatorname{Han}^{1}$ \\ ${ }^{1}$ Qingdao Municipal Center for Disease Control and Prevention \\ ${ }^{2}$ Qingdao Women and Children's Hospital
}

June 2, 2020

\begin{abstract}
Tracing and isolation of close contacts is used to control outbreaks of coronavirus disease 2019 (COVID-19) in China. However, risk factors associated with occurrence of COVID-19 among close contacts have not been well described. 106 household contacts were included in this study, of whom 19 were developed into COVID-19 cases and the secondary attack rate was 17.9\%. Multivariable analysis showed increasing risk of occurrence of COVID-19 among household contacts associated with female of index patients (Adjusted Hazard Ratio $[\mathrm{aHR}]=5.61,95 \% \mathrm{CI}=1.51-20.83)$, critical disease of index patients $([\mathrm{aHR}]$ $=7.58,95 \% \mathrm{CI}=1.66-34.66)$, effective contact duration with index patients $>2$ days $([\mathrm{aHR}]=4.21,95 \% \mathrm{CI}=1.29-13.73)$, and effective contact duration $>11$ days $([\mathrm{aHR}]=17.88,95 \% \mathrm{CI}=3.26-98.01)$. The sex and disease severity of index COVID-19 patients, and longer effective contact duration with COVID-19 confirmed cases could help epidemiologists to identify potential COVID-19 case among household contacts at an early stage.
\end{abstract}

\section{Hosted file}

Manuscript.doc available at https://authorea.com/users/329091/articles/456170-risk-factorsassociated-with-occurrence-of-covid-19-among-household-persons-exposed-to-patients-withconfirmed-covid-19-in-qingdao-municipal-china

\section{Hosted file}

Tables.docx available at https://authorea.com/users/329091/articles/456170-risk-factorsassociated-with-occurrence-of-covid-19-among-household-persons-exposed-to-patients-withconfirmed-covid-19-in-qingdao-municipal-china 